\title{
A Review of Simulation-based Optimisation in Maintenance Operations
}

\author{
Abdullah Alrabghi and Ashutosh Tiwari \\ Manufacturing and Materials Department \\ Cranfield University \\ Cranfield, United Kingdom \\ a.alrabghi@cranfield.ac.uk, A.Tiwari@cranfield.ac.uk
}

\begin{abstract}
This paper aims to report the state of the art of research in simulation-based optimisation of maintenance operations by systematically classifying the published literature and outlining various tools and techniques used by researchers to model and optimise maintenance operations. The authors investigate the critical elements and aspects of maintenance systems and how well they are represented in the literature as well as various approaches to problem formulation. On this basis, the paper identifies the current gaps and discusses future prospects. It is observed that discrete event is the most widely used simulation technique while nontraditional optimisation algorithms such as genetic algorithms and simulated annealing are the most reported optimisation techniques. Little attention has been paid to the discussion and analysis of different elements in the maintenance environment and their effect on the maintenance system behaviour. There is a need for verifying suggested models through real life case studies.
\end{abstract}

Keywords- maintenance; simulation; moedlling; optimisation

\section{INTRODUCTION}

As competition is increasing and the financial crisis is hitting businesses around the globe, manufacturers strive to operate more efficiently in order to sustain. This usually means producing more with the same resources or less. Increasing the efficiency of maintenance operations is one of the potential areas that received growing attention throughout the years.

Although research on maintenance optimisation was established decades ago [1], the area of simulation-based optimisation in maintenance is becoming an emerging trend [2; 3]. Roger [4] defines simulation based optimisation as an approach whereby an optimisation engine provides the input factors for the simulation program. The simulation will run and provide the results of the optimisation objective function. This process will continue iteratively between the simulation program and the optimisation engine until it results in a satisfied solution or a termination due to prescribed conditions.

Dekker [1] provided a comprehensive view and analysis of maintenance optimisation models and applications. It is interesting to note that in his work, simulation has not been mentioned and the emphasis was on mathematical models only. More recently, Sharma et al. [2] observed that there is a potential as well as a growing interest amongst researchers to utilise simulation in optimising maintenance systems. The advancement in technology enabled researches to use powerful computers and software in continuous decreasing costs. Simulation delivers an advantage over analytical approaches because many maintenance policies are not analytically traceable $[3 ; 5]$. Furthermore, it allows experimentation and better understanding of complex systems [6].

On the other hand, Andijani and Duffuaa [7] evaluated simulation studies in maintenance systems in terms of adherence to sound modelling principles such as program verification and validation. Alabdulkarim et al. [8] reviewed the applications of simulation in maintenance systems and categorised it according to the purpose of the study. Their research confirms that research on maintenance simulation is steadily rising. Additionally, they observed that research on the combined use of simulation and optimisation is limited.

It is evident that previous reviews focused either on maintenance optimisation or maintenance simulation. Considering the potential of simulation based optimisation technique in improving maintenance systems, this work is the first to analyse and describe available literature on the combined use of simulation and optimisation in maintenance operations.

\section{Literature ReVIEW Methodology}

\section{A. Research Aim and Scope}

This research aims to identify and summarise available literature on simulation-based optimisation of maintenance operations. Thus the scope is focused on research that includes building a simulation model of maintenance operations and then connecting the simulation model to an optimisation algorithm.

Research that aims to identify optimal solutions based solely on design of experiments and response surface methodology lies outside the research scope. Similarly, research that focuses on the technical aspects of maintenance as opposed to operational aspects is considered irrelevant. There have been attempts to simulate maintenance operations through static system models, usually using monte-carlo simulation $[9 ; 10]$. As time is a significant variable in maintenance operations, only attempts to model it 
through dynamic system models are within the scope of this research.

\section{B. Research Methodology and Results}

A systematic research was conducted by searching for the following keywords in article titles: (maintain* and optim* and simulat*) and (maintenance and optim* and simulat*). The search covered relevant scholarly databases such as Scopus, ABI Inform Complete (ProQuest) and Business Source Complete (EBSCO). After removing duplicate records, the search resulted in 83 documents. Resulting literature was screened first through titles and abstracts to remove irrelevant documents. A further comprehensive screening was conducted through the full documents which yielded 28 articles [11-38].

\section{OVERVIEW OF RESULTS}

Simulation-based optimisation studies covered a wide range of applications. Roux et al. [23] studied a simple unrepairable system where replacement policies are only applicable. Xiang et al. [11] studied a repairable system where preventive maintenance and condition-based maintenance policies where investigated. The focus of Hani et al. [28] and Allaoui and Artiba [36] research was on maintenance scheduling by evaluating various priority rules and heuristics. Rezg et al. [31] main focus was on determining the preventive maintenance frequency and buffer size that allows the application of just-in-time configuration efficiently in the production system. Sarker and Haque [37] examined maintenance spare provisioning policies and its impact on the effectiveness of maintenance operations. However, on the whole the research is limited in terms of covering main maintenance decisions such as comparing and selecting the optimum maintenance policies in multi-component systems and determining the optimum maintenance resources.

Case studies were conducted in semiconductor manufacturing systems $[13 ; 16 ; 35]$, automotive parts industry [24], plastic industry [26] and train maintenance facilities $[22 ; 28]$. It is however, important to note that most researchers tended to use academic case studies $[17 ; 19-21$; $23 ; 31 ; 36 ; 37]$.

While most studies examined maintenance in a production context, few researchers examined maintenance operations for working products such as ships or aircrafts. Johansson and Jagstam [15] examined military equipment while Gupta and Lawsirirat [29] examined a general multicomponent system. Both studies reported the shift towards product service system as the main motivation for their research. El Hayek et al. [30] demonstrated the effectiveness of simulation based optimisation for planning maintenance operations for an aircraft gas-turbine. It is observed that there are several differences between maintenance in a production context and maintenance in a product service system context. In the former issues such as bottle necks, buffer size and parts waiting in progress have an impact on maintenance planning [12]. In contrast, logistics and transportation are main issues in product service systems.

\section{RESEARCH TRENDS In Simulation USED With OPTIMISATION}

\section{A. Simulation Techniques}

Discrete event simulation dominates the literature as it was used alone or combined with other modelling techniques by more than $70 \%$ of researchers (see Figure 1). This should not come as a surprise since it is the most popular technique in modelling manufacturing systems [39]. Some researchers combined discrete event simulation with other modelling techniques to gain further advantages [14]. Xiang et al. [11] and Gharbi and Kenne [32] built a discrete event model to represent the general manufacturing system with the machine degradation process modelled as a continuous element to reflect the fact that machines age as time passes by. On the other hand, other simulation techniques such as dynamic programming [13; 35], continuous simulation [29], markov chains [33] and petri-nets [17] were reported in few articles.

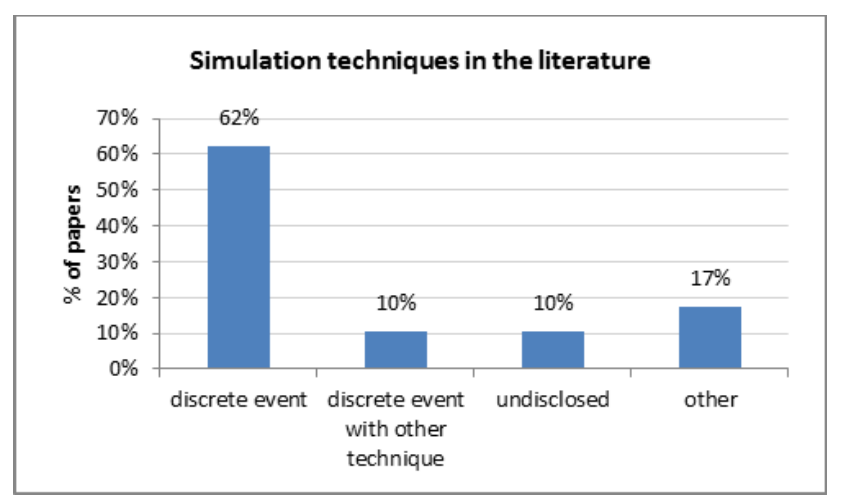

Figure 1. Simulation techniques in the literature (28 papers)

\section{B. Elements Modelled in the Simulation}

Modelling maintenance operations was approached differently amongst researchers as they tried to balance between mimicking the behaviour of the real system and making reasonable simplifying assumptions. The decision of including an element should depend on the level of effect it has on the desired simulation output [40]. In general, appropriate discussion and analysis of elements and their effect on the system was insignificant.

Figure 2 illustrates the wide range of variances in terms of elements considered in the simulation model. The work of Hennequin et al. [21] proved novel in terms of modelling uncertainty. Fuzzy logic was included in the model to reflect the uncertainty associated with maintenance crew skills and experiences. 


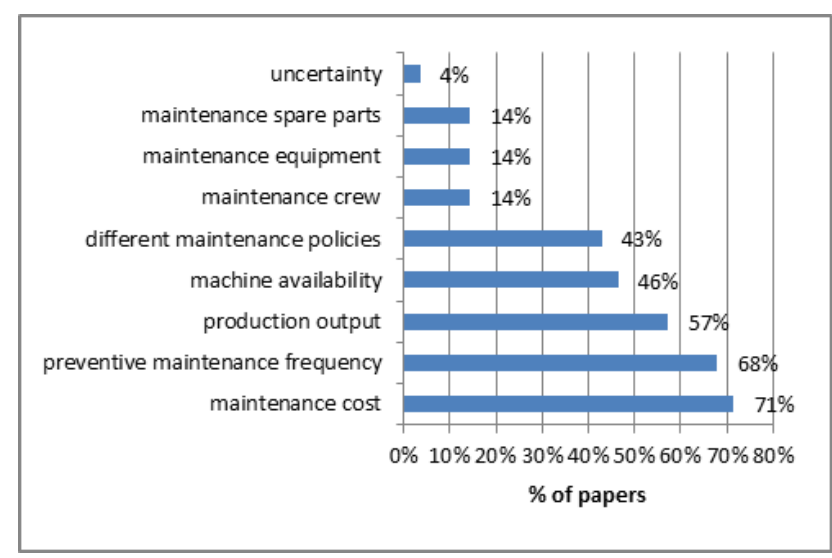

Figure 2. Elements modelled in the simulation (28 papers)

Although maintenance resources such as technicians, spare parts and equipment have a direct effect on maintenance cost and scheduling [41-43], only few researchers incorporated them in the simulation model. In fact, the assumption of readily available maintenance resources is fairly common $[12 ; 14 ; 23 ; 31 ; 36]$.

An equally significant aspect is the modelling of machine aging process. Some researchers simplified it by designing only two states for the machine, either working or broken [26]. Additionally, the machine is regarded as good as new after undertaking maintenance tasks. On the other hand, El Hayek et al [30] considered an improvement factor that incorporates imperfect maintenance. Therefore the machine status after maintenance tasks will not be regarded as good as new, rather it lies somewhere between a broken machine and a new machine depending on the random improvement factor. Furthermore, the duration between preventive maintenance tasks is reduced as the machine ages.

Accurate modelling of machine degradation process becomes essential for examining condition-based maintenance where an inspection is conducted periodically to decide which maintenance tasks should be executed [44]. Alternatively, sensors could provide indicators on machines' health such as vibration magnitude and temperature in real time [11]. When indicators' reading exceed a specific threshold, a maintenance task is triggered. Guizzi et al. [20] simulated condition based maintenance via discrete event simulation with the aim of investigating how inspection cost affects the optimum inspection intervals. In their study, the limitation of discrete event simulation is overcome by triggering special events that increase the machine wear at predetermined intervals. Xiang et al. [11] conducted a comparison between preventive maintenance and condition based maintenance for a single component. Although the applications of condition based maintenance are increasing in the industry [44], it is evident that it is poorly covered in the literature.

\section{RESEARCH TRENS IN OPTIMISATION}

\section{A. Optimisation Techniques}

Similar to simulation techniques, not all researchers disclosed the optimisation technique they used $[16 ; 35 ; 37]$. Manual optimisation was reported extensively where simulation runs were conducted whilst changing variables values manually in gradual steps $[17 ; 18 ; 31 ; 33]$. As can be expected, manual search is limited in terms of search space and number of variables. On the other hand, direct search methods such as Nelder-Mead method [14; 23] and cyclic coordinate method [11] were applied to simple manufacturing systems.

As the complexity of maintenance systems increased [3; 5], non-traditional optimisation algorithms emerged as a better optimisation technique [38; 45]. As shown in Figure 3, Non-traditional algorithms such as genetic algorithms [12; $27 ; 28 ; 34]$ and simulated annealing [36] were the most reported optimisation techniques. Ali et al. [25] and Guuizzi et al. [20] approach has a significant advantage. In their study they connected the simulation software to a specialised optimisation tool that allowed the utilisation of multiple optimisation algorithms including Non-traditional algorithms.

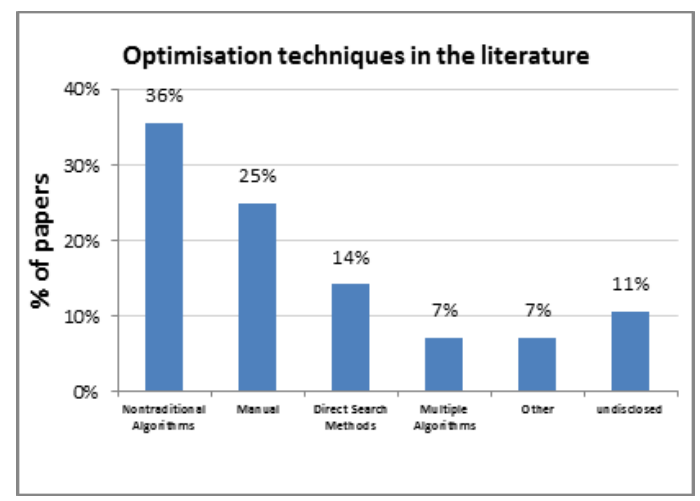

Figure 3. optimisation techniques in the literature (28 papers)

\section{B. Optimisation Problem Formation}

Minimising maintenance cost was reported as an objective in more than $70 \%$ of the studies (see Figure 4). In fact it was the only optimisation objective in around third of the studies, see for example: [11;23; 29; 34]. Arab et al. [12] correctly argues that maintenance is a part of the manufacturing system and considering maintenance cost alone is not sufficient. Roux et al. [14] and Boulet et al. [18] included maximising machines availability as an optimisation objective. However, maximum machine availability does not necessarily lead to maximum production throughput, which is an optimisation objective in several recent studies $[12 ; 16 ; 17 ; 25]$. Oyarbide-Zubillaga et al. [24] considered a holistic approach where the total cost and profit of the system is evaluated. The costs of maintenance tasks as well as defective products contribute to the cost function whereas the profit is calculated by the 
number of non-defective items produced. Azadivar and Shu [38] optimised a maintenance system with the objective of maximising the percentage of jobs delivered on time.

Nearly half of the studies focused on determining the optimum preventive maintenance frequency. Usually reactive maintenance is fixed at a higher cost than preventive maintenance and the optimum preventive maintenance frequency that reduces the total maintenance cost is sought $[16 ; 19 ; 21 ; 24]$. The work of several authors $[17 ; 31 ; 38]$ show that buffer size have an impact on the performance of maintenance operations. Another significant variable that received little attention is maintenance queuing and priority rules. This may be due to the fact that maintenance resources were not considered in the simulation model as shown above. However, it is evident that assigning different priorities to machines when maintenance resources are occupied have a direct effect on maintenance performance $[13 ; 17]$.

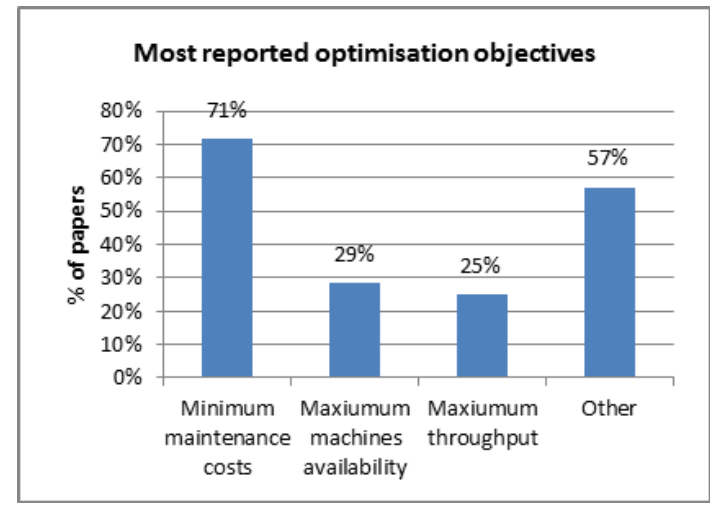

Figure 4. Most reported optimisation objectives (28 papers)

It can be seen from the above analysis that optimal problem formulation varied significantly. This might be due to the nature and purpose of the study. For instance, Ramírez-Hernandez and Fernandez [13] formulated the optimisation objective purely on production measures namely to minimise both machine cycle time and wait in progress. The purpose of their study could have been to support a quality initiative without a particular interest in cutting maintenance resources in the factory. On the contrary, Hani et al. [22] examined a train maintenance facility where the focus was on minimising the parts immobilization time as well as minimising occupation rates for maintenance workshops. Nevertheless, limited discussion of the optimal problem formulation was observed in the literature.

\section{SUMMARY OF KEY FINDINGS}

The systematic literature review highlighted a number of key findings summarised below:

1- A range of simulation based optimisation applications in maintenance systems across various industries were covered such as semiconductor manufacturing, automotive parts, plastic industry, train maintenance facilities and product service systems such as aircraft gas-turbine and military equipment.

2- Limited research is directed towards supporting maintenance decisions at the operational level. For instance, comparing and selecting the optimum maintenance policy.

3- Simulation based optimisation has a significant advantage over mathematical approaches as it is more capable of representing complex systems such as maintenance systems.

4- Few real life case studies were reported. The academic cases that dominate the literature such as a single machine producing a single product are oversimplified and do not reflect the complexity and interactions in real systems.

5- A vast majority of researchers used discrete event simulation to model maintenance operations whereas nontraditional optimisation algorithms were the most reported optimisation techniques.

6- Simulation and optimisation tools and techniques were not always detailed.

7- Investigating condition based maintenance as a maintenance policy for multi-component systems in a production context is poorly covered in the literature.

8- Successful implementation of simulation based optimisation requires appropriate discussion and analysis of elements surrounding maintenance operations and their effect on the desired output.

9- Incorporating maintenance resources in the simulation model is limited.

10- A considerable effort was directed towards determining the optimum preventive maintenance frequency.

11- Little attention has been paid to the utilisation of multiple optimisation algorithms.

12- The formulation of optimisation problems including choosing the objective function, decision variables and constraints is rarely discussed.

\section{CONCLUSIONS AND FUTURE RESEARCH}

The aim of this research is to report the state of the art of research in simulation-based optimisation of maintenance operations by systematically classifying the published literature, outlining research gaps and guiding future research. Simulation based optimisation has been successfully applied to maintenance operations. Despite the limited research in the developing field, it appears to have a high potential due to its ability to model complex maintenance systems.

The findings outlined in this research provide direction for future work. There seems to be a need for a detailed analysis of factors that have a significant impact on maintenance performance both in a production context and in product-service systems. Similarly, there is a need for a framework that allows experimenting with different maintenance policies, especially condition based maintenance whilst utilising advanced tools that offer multiple optimisation algorithms. More applications can be conducted on real life case studies. 


\section{ACKNOWLEDGMENTS}

The authors would like to thank the Ministry of Higher Education in Saudi Arabia for funding this research.

\section{REFERENCES}

[1] Dekker, R. (1996), "Applications of Maintenance Optimization Models: A Review and Analysis", Reliability Engineering and System Safety., vol. 52, no. 3, pp. 229 - 240.

[2] Sharma, A., Yadava, G. and Deshmukh, S. (2011), "A literature review and future perspectives on maintenance optimization", Journal of Quality in Maintenance Engineering, vol. 17, no. 1, pp. 5-25.

[3] Garg, A. and Deshmukh, S. (2006), "Maintenance management: literature review and directions", Journal of Quality in Maintenance Engineering, vol. 12, no. 3, pp. 205-238.

[4] Rogers, P. (2002), "Optimum-seeking simulation in the design and control of manufacturing systems: experience with OptQuest for Arena", Proceedings of the Winter Simulation Conference, 2002, Vol. 2, 8-11 Dec 2002, San Diego, California, USA, pp. 1142-1150.

[5] Nicolai, R. P. and Dekker, R. (2008), "Optimal maintenance of multicomponent systems: a review", in Kobbacy, K. and Murthy, D. N. (eds.) Complex system maintenance handbook, Springer, London, pp. 263-286.

[6] Sebastian, W. (2006), "Simulation of Manufacturing Processes", in Sauer, W. (ed.) Electronics process technology production modelling, simulation and optimisation, Springer, London, pp. 119-172.

[7] Andijani, A. and Duffuaa, S. (2002), "Critical evaluation of simulation studies in maintenance systems.", Production Planning and Control, vol. 13, no. 4, pp. 336-341.

[8] Alabdulkarim, A. A., Ball, P. D. and Tiwari, A. (2013), "Applications of Simulation in Maintenance Research", World Journal of Modelling and Simulation, vol. 09, no. 01, [Article In Press].

[9] Marseguerra, M., Zio, E. and Podofillini, L. (2002), "Condition-based maintenance optimization by means of genetic algorithms and Monte Carlo simulation", Reliability Engineering \& System Safety, vol. 77, no. 2, pp. 151-165.

[10] Wang, L., Chu, J. and Mao, W. (2008), "An optimum condition-based replacement and spare provisioning policy based on Markov chains", Journal of Quality in Maintenance Engineering, vol. 14, no. 4, pp. $387-401$.

[11] Xiang, Y., Cassady, C. R. and Pohl, E. A. (2012), "Optimal maintenance policies for systems subject to a Markovian operating environment", Computers and Industrial Engineering, vol. 62, no. 1, pp. 190-197.

[12] Arab, A., Ismail, N. and Lee, L. S. (2011), "Maintenance scheduling incorporating dynamics of production system and real-time information from workstations", Journal of Intelligent Manufacturing, vol. [Article In Press].

[13] Ramírez-Hernández, J. A. and Fernandez, E. (2010), "Optimization of preventive maintenance scheduling in semiconductor manufacturing models using a simulation-based approximate dynamic programming approach", Proceedings of the IEEE Conference on Decision and Control, 15-17 Dec 2010, Atlanta, pp. 3944-3949.

[14] Roux, O., Duvivier, D., Quesnel, G. and Ramat, E. (2010), "Optimization of preventive maintenance through a combined maintenance-production simulation model", International Journal of Production Economics, vol. [Article In Press].

[15] Johansson, E. C. and Jägstam, M. (2010), "Maintenance planning using simulation-based optimization", Spring Simulation Multiconference 2010, SpringSim'10, 11-15 April 2010, Orlando, .

[16] Ramírez-Hernández, J. A., Crabtree, J., Yao, X., Fernandez, E., Fu, M. C., Janakiram, M., Marcus, S. I., O'Connor, M. and Patel, N. (2010), "Optimal preventive maintenance scheduling in semiconductor manufacturing systems: Software tool and simulation case studies", IEEE Transactions on Semiconductor Manufacturing, vol. 23, no. 3, pp. 477-489.

[17] Lei, Y., Liu, J., Ni, J. and Lee, J. (2010), "Production line simulation using STPN for maintenance scheduling", Journal of Intelligent Manufacturing, vol. 21, no. 2, pp. 213-221.

[18] Boulet, J. F., Gharbi, A. and Kenn, J. P. (2009), "Multiobjective optimization in an unreliable failure-prone manufacturing system", Journal of Quality in Maintenance Engineering, vol. 15, no. 4, pp. 397-411.

[19] Boschian, V., Rezg, N. and Chelbi, A. (2009), "Contribution of simulation to the optimization of maintenance strategies for a randomly failing production system", European Journal of Operational Research, vol. 197, no. 3, pp. 1142-1149.

[20] Guizzi, G., Gallo, M. and Zoppoli, P. (2009), "Condition based maintenance: Simulation and optimization", Proceedings of the 8th WSEAS International Conference on System Science and Simulation in Engineering, ICOSSSE '09, 17-19 Oct 2009, Genova, pp. 319-325.

[21] Hennequin, S., Arango, G. and Rezg, N. (2009), "Optimization of imperfect maintenance based on fuzzy logic for a single-stage singleproduct production system", Journal of Quality in Maintenance Engineering, vol. 15, no. 4, pp. 412-429.

[22] Hani, Y., Amodeo, L., Yalaoui, F. and Chen, H. (2008), "Simulation based optimization of a train maintenance facility", Journal of Intelligent Manufacturing, vol. 19, no. 3, pp. 293-300.

[23] Roux, O., Jamali, M. A., Kadi, D. A. and Châtelet, E. (2008), "Development of simulation and optimization platform to analyse maintenance policies performances for manufacturing systems", International Journal of Computer Integrated Manufacturing, vol. 21, no. 4, pp. 407-414.

[24] Oyarbide-Zubillaga, A., Goti, A. and Sanchez, A. (2008), "Preventive maintenance optimisation of multi-equipment manufacturing systems by combining discrete event simulation and multi-objective evolutionary algorithms", Production Planning and Control, vol. 19, no. 4, pp. 342-355.

[25] Ali, A., Chen, X., Yang, Z., Lee, J. and Jun, N. (2008), "Optimized maintenance design for manufacturing performance improvement using simulation", Proceedings - Winter Simulation Conference, 7-10 Dec 2008, Miami, pp. 1811-1819.

[26] Goti, A., Oyarbide-Zubillaga, A. and Sánchez, A. (2007), "Optimizing preventive maintenance by combining discrete event simulation and genetic algorithms", Hydrocarbon Processing, vol. 86, no. 10 , pp. $115-116+118+120-122$.

[27] Oyarbide-Zubillaga, A., Goti, A. and Sánchez, A. (2007), "Determination of the optimal maintenance frequency for a system composed by $\mathrm{N}$-machines by using discrete event simulation and genetic algorithms", Proceedings of the European Safety and Reliability Conference 2007, ESREL 2007 - Risk, Reliability and Societal Safety, Vol. 1, 25-27 June 2007, Stavanger, pp. 297-304.

[28] Hani, Y., Chehade, H., Amodeo, L. and Yalaoui, F. (2007), "Simulation based optimization of a train maintenance facility model using genetic algorithms", Proceedings - ICSSSM'06: 2006 International Conference on Service Systems and Service Management, Vol. 1, 25-27 Oct 2006, Troyes, pp. 513-518.

[29] Gupta, A. and Lawsirirat, C. (2006), "Strategically optimum maintenance of monitoring-enabled multi-component systems using continuous-time jump deterioration models", Journal of Quality in Maintenance Engineering, vol. 12, no. 3, pp. 306-329.

[30] El Hayek, M., Van Voorthuysen, E. and Kelly, D. W. (2005), "Optimizing life cycle cost of complex machinery with rotable modules using simulation", Journal of Quality in Maintenance Engineering, vol. 11, no. 4, pp. 333-347.

[31] Rezg, N., Chelbi, A. and Xie, X. (2005), "Modeling and optimizing a joint inventory control and preventive maintenance strategy for a randomly failing production unit: Analytical and simulation approaches", International Journal of Computer Integrated Manufacturing, vol. 18, no. 2-3, pp. 225-235. 
[32] Gharbi, A. and Kenné, J. P. (2005), "Maintenance scheduling and production control of multiple-machine manufacturing systems", Computers and Industrial Engineering, vol. 48, no. 4, pp. 693-707.

[33] Kenné, J. P. and Gharbi, A. (2004), "Stohastic optimal production control problem with corrective maintenance", Computers and Industrial Engineering, vol. 46, no. 4 SPEC. ISS., pp. 865-875.

[34] Rezg, N., Xie, X. and Mati, Y. (2004), "Joint optimization of preventive maintenance and inventory control in a production line using simulation", International Journal of Production Research, vol. 42, no. 10, pp. 2029-2046.

[35] Yao, X., Fernández-Gaucherand, E., Fu, M. C. and Marcus, S. I. (2004), "Optimal preventive maintenance scheduling in semiconductor manufacturing", IEEE Transactions on Semiconductor Manufacturing, vol. 17, no. 3, pp. 345-356.

[36] Allaoui, H. and Artiba, A. (2004), "Integrating simulation and optimization to schedule a hybrid flow shop with maintenance constraints", Computers and Industrial Engineering, vol. 47, no. 4, pp. 431-450.

[37] Sarker, R. and Haque, A. (2000), "Optimization of maintenance and spare provisioning policy using simulation", Applied Mathematical Modelling, vol. 24, no. 10, pp. 751-760.

[38] Azadivar, F. and Shu, J. V. (1998), "Use of simulation in optimization of maintenance policies", Winter Simulation Conference Proceedings, Vol. 2, 13-16 Dec 1998, Washington, pp. 1061-1067.
[39] Jahangirian, M., Eldabi, T., Naseer, A., Stergioulas, L. K. and Young, T. (2010), "Simulation in manufacturing and business: A review", European Journal of Operational Research, vol. 203, no. 1, pp. 1-13.

[40] Robinson, S. (2007), Simulation : the practice of model development and use, Wiley, Chichester.

[41] Bruzzone, A. and Bocca, E. (2012), "Innovative solutions based on simulation combined with optimization techniques for maintenance service management within complex systems", International Journal of Modeling, Simulation, and Scientific Computing, vol. 3, no. 2.

[42] Verma, A., Srividya, A. and Gaonkar, R. (2007), "Maintenance and replacement interval optimization using possibilistic approach", International Journal of Modelling and Simulation, vol. 27, no. 2, pp. 193-199.

[43] Duffuaa, S., Ben-Daya, M., Al-Sultan, K. and Andijani, A. (2001), "A generic conceptual simulation model for maintenance systems", Journal of Quality in Maintenance Engineering, vol. 7, no. 3, pp. 207219.

[44] Wang, W. (2008), "Condition-based maintenance modelling", in Kobbacy, K. and Murthy, D. N. (eds.) Complex System Maintenance Handbook, Springer, London, pp. 111-131.

[45] Deb, K. (2005), Optimization for engineering design : algorithms and examples, Prentice-Hall of India Private Limited, New Delhi. 
2013-06-10

\title{
A review of simulation-based optimisation in maintenance operations
}

\author{
Alrabghi, Abdullah
}

IEEE

Abdullah Alrabghi and Ashutosh Tiwari. A review of simulation-based optimisation in maintenance operations. 2013 UKSim 15th International Conference on Computer Modelling and Simulation (UKSim 2013), 10-12 April 2013, Cambridge, UK

https://doi.org/10.1109/UKSim.2013.27

Downloaded from Cranfield Library Services E-Repository 